Dr. Carlos E. Delpiazzo $\left(^{*}\right)$

\title{
Acerca del Habeas data propio e impropio
}

(*) Doctor en

Derecho y Ciencias Sociales por la Universidad Mayor de la República Oriental del Uruguay. Profesor de Derecho Administrativo y Director del Instituto de Derecho Administrativo y del Instituto de Derecho Informático en la $\mathrm{Fa}$ cultad de Derecho de dicha Universidad.

\section{I). Introducción}

La expresión "habeas data" está parcialmente tomada del antiguo instituto del "habeas corpus", proviniendo el primer vocablo del latín (con el significado de conservar, guardar o traer) y el segundo del inglés (alusivo a información o datos) ${ }^{1}$.

De acuerdo al art. 17 de la Constitución, "En caso de prisión indebida, el interesado o cualquier persona podrá interponer ante el Juez competente el recurso de habeas corpus, a fin de que la autoridad aprehensora explique y justifique de inmediato el motivo legal de la aprehensión, estándose a lo que decida el Juez indicado".

Por lo tanto, haciendo pie en dicha disposición, el habeas data puede considerarse como la vía de garantía tendiente a obtener del Juez competente la exhibición de determinada información.

No obstante, la doctrina ha reservado la denominación habeas data para designar la acción jurisdiccional destinada a la protección de los datos personales ${ }^{2}$.

Por extensión, el mismo nombre habeas data se ha usado para designar la acción juris-

Miguel Angel EKMEKDJIAN y Calogero PIZZOLO - "Habeas data. El derecho a la intimidad frente a la revolución informática” (Depalma, Buenos Aires, 1996), pág. 1.

2 Oscar PUCCINELLI - "El habeas data en Indoiberoamérica" (Temis, Bogotá, 1999), pág. 65 y sigtes.; Osvaldo Alfredo GOZANI (Coordinador) - "La defensa de la intimidad y de los datos personales a través del habeas data” (Ediar, Buenos Aires, 2001), pág. 13 y sigtes.; Alvaro CANALES GIL - "La protección de datos personales como derecho fundamental”, en anuario "Derecho Informático" (F.C.U., Montevideo, 2004), tomo IV, págs. 264 y 265; Miguel Angel DAVARA RODRIGUEZ - "Manual de Derecho Informático" (Thomson - Aranzadi, Navarra, 2004), 6a edición, pág. 43 y sigtes.; Miguel Angel EKMEKDJIAN y Calogero PIZZOLO - "Habeas data. El derecho a la intimidad frente a la revolución informática" cit., pág. 5 y sigtes.; Julio TELLEZ VALDES - "Derecho Informático" (Mc Graw Hill, México, 2004), $3^{a}$ edición, pág. 57 y sigtes.; María del Carmen GUERRERO PICO - "El impacto de Internet en el derecho fundamental a la protección de datos" (Thomson - Civitas, Navarra, 2006), pág. 21 y sigtes.; y Alfonso ORTEGA GIMENEZ - "El derecho a la protección de datos de carácter personal en Internet", en X Congreso Iberoamericano de Derecho e Informática (Santiago de Chile, 2004), pág. 223 y sigtes. 
diccional que tiene por objeto obtener el acceso a los archivos y registros documentales de la Administración ${ }^{3}$.

Mientras que en sentido propio el habeas data traduce el ejercicio del derecho a la privacidad o a la intimidad, del que es emanación el derecho a la protección de los datos personales, en sentido impropio se trata del ejercicio del desprendimiento del derecho a la información consistente en el derecho al acceso a la información pública.

\section{II). Acceso a la información}

\section{Distinción entre información pública y privada}

La característica sobresaliente de la sociedad de nuestros días es que la información se ha convertido en una nueva forma de energía, de poder y de producción ${ }^{4}$. Ya nadie duda que, junto al poder de las armas y del dinero, hoy la información es un elemento central, incluso para el poder militar y el poder económico, constituyéndose en sí misma en una novedosa forma de bien valorable económicamente. Asimismo, junto a los tres sectores tradicionales de la agricultura, de la industria y de los servicios, es reconocida actualmente la existencia de un cuarto sector, el sector cuaternario, que es el de la información.

Es que "en la sociedad contemporánea la información se presenta con caracteres hasta ahora desconocidos en la historia de la civilización humana en lo concerniente a su cantidad, su variedad, su rapidez, su persistencia y, finalmente, y este es el carácter decisivo y condicionante de todos los demás, a su automatización" 5.

En ese contexto, a los efectos de los desarrollos subsiguientes, interesa distinguir entre la información pública y la privada o particular.

Tres principios generales convocan a la accesibilidad a la información pública en poder de las Administraciones, siempre que la misma no se encuentre limitada mediante ley dictada por razones de interés general.

En primer lugar, corresponde mencionar el clásico principio de publicidad del obrar administrativo.

Según se ha destacado con acierto, el principio de publicidad deriva de la forma republicana de gobierno ${ }^{6} \mathrm{y}$ "las restricciones a la publicidad deben atender a dos criterios: por un lado, deben ser más débiles cuanto mayor sea el interés individual

Carlos E. DELPIAZZO - "Automatización de la actividad administrativa en el marco de la reforma del Estado", en Anuario de Derecho Administrativo (Montevideo, 1998), tomo VI, pág. 22.

Vittorio FROSINI - “Cibernética, Derecho y Sociedad” (Tecnos, Madrid, 1982), pág. 173 y sigtes.

Vittorio FROSINI - "Informática y Derecho” (Temis, Bogotá, 1988), pág. 29.

Felipe ROTONDO TORNARIA - "Aproximación a la participación del administrado a la luz de los principios generales”, en Rev. de la Facultad de Derecho y C.S., Año XXVI, No 1, pág. 63. 
del que pide información; por otro lado, deben ser más débiles cuanto mayor sea la responsabilidad del solicitante por el buen funcionamiento del ente administrativo requerido. $\mathrm{Y}$ en ambos casos, la restricción debe ser motivada en una razón que sea suficientemente importante como para compensar la razón genérica que aconseja la publicidad como resorte esencial del sistema republicano. No hay que olvidar que la restricción debe tener siempre un motivo legítimo, derivar de un acto inspirado en alguna razón atendible... Pero si no hay razones para la restricción, aunque tampoco existan motivos especiales para la publicidad, ésta procede; precisamente porque ésta es la solución de principio bajo el sistema republicano" ${ }^{7}$.

En segundo lugar, íntimamente asociado al principio de publicidad, el principio de transparencia supone algo más. Cuando se habla de transparencia de la gestión administrativa, "se quiere dar un paso más respecto a la publicidad... como que la publicidad implica mostrar pero la transparencia implica algo más que mostrar, implica dejar ver; simplemente que el actuar de la Administración se deje ver como a través de un cristal" ${ }^{8}$.

Más allá de la publicidad, la transparencia refiere a la diafanidad del obrar público, permitiendo ver con claridad el actuar de la Administración en la disposición y uso de los fondos públicos y en el obrar de sus funcionarios; "constituye una consecuencia de la muy elemental presunción de que el gobierno pertenece al pueblo, quien tiene derecho a saber qué hacen los servidores públicos, por qué y cómo lo hacen" 9 .

Según se ha destacado ${ }^{10}$, la transparencia se asocia a lo que es visible y accesible, a lo que puede ser conocido y comprendido, por contraposición a lo cerrado, misterioso, inaccesible o inexplicable. Igualmente, la transparencia se asocia a una carga afectiva ligada a la tranquilidad y serenidad provocada por todo aquello que se domina y racionaliza, por oposición a la angustia y perturbación de lo misterioso y desconocido.

En tercer lugar, interesa destacar que la accesibilidad por todos a la información pública y, más aún, al quehacer de las Administraciones públicas está impuesta por el principio de participación ${ }^{11}$.

Horacio CASSINELLI MUÑOZ - "El principio de publicidad de la gestión administrativa” cit., tomo 58, págs. 165 y 166; y Elbio J. LOPEZ ROCCA - "Publicidad y secreto en la Administración Pública”, en Rev. de Derecho Público, Año 2003, No 24, pág. 39 y sigtes.

8 Carlos E. DELPIAZZO - "Transparencia en la contratación administrativa”, en "Liber Amicorum Discipulorumque José Aníbal Cagnoni” (F.C.U., Montevideo, 2005), pág. 138 y sigtes.; "La regulación legal del control social y transparencia”, en Rev. de Antiguos Alumnos del IEEM, Año 5, No 1, pág. 29 y sigtes.; "Control social de la Administración y transparencia”, en Rev. Ius Publicum (Santiago de Chile, 2003), No 11, pág. 43 y sigtes.; y "De la publicidad a la transparencia en la gestión administrativa", en Rev. de Derecho de la Universidad de Montevideo (Montevideo, 2003), Año II, No 3, pág. 113 y sigtes.

9 Richard S WERKSMAN y Carlos MAMFRONI - "La transparencia y la Convención Interamericana contra la Corrupción”, en Rev. de Derecho Administrativo (Buenos Aires, 1996), Año 8, No 21-23, pág. 346.

10 Jaime RODRIGUEZ-ARANA MUÑOZ - "La dimensión ética” (Dykinson, Madrid, 2001), pág. 312.

11 Carlos E. DELPIAZZO - "Dimensión tecnológica de la participación del administrado en el Derecho uruguayo", en Rev. Iberoamericana de Derecho Público y Administrativo (San José de Costa Rica, 2005), No 5, pág. 63 y sigtes.; y en Rogerio GESTA LEAL (Organizador) - "Administraçao Pública e Participaçao Social na América Latina” (Edunisc, Santa Cruz do Sul, 2005), pág. 117 y sigtes. 
De acuerdo a dicho principio, existiendo accesibilidad real, corresponde que los habitantes sean informados y consultados en los asuntos que les conciernen ${ }^{12}$.

Por otra parte, la información privada comprende datos que afectan a la vida íntima de la persona, pero también a todos aquellos que identifiquen o puedan identificarla $y$, al hacerlo, puedan ser susceptibles de producir, en determinadas circunstancias, una amenaza para el individuo. Consecuentemente, faculta a la persona a decidir cuáles proporciona a un tercero y para saber quién los posee y para qué finalidad concreta. El ejercicio de ese poder se manifiesta en la posibilidad de consentir la colecta, tratamiento y uso de los datos, así como en el derecho de acceso, rectificación, cancelación y oposición ${ }^{13}$.

De este modo, la reserva de la información privada o de carácter personal se opone a la publicidad que, por principio, tiene la información pública, distinción que, desde el punto de vista práctico, se ve diluida por el avance de Internet ${ }^{14}$.

Abonan la confidencialidad de la información de carácter personal -erigida ella misma como principio general- un conjunto de otros principios generales de Derecho que, con distintos grados de explicitación, son reconocidos a nivel comparado ${ }^{15}$.

En primer lugar, corresponde mencionar el principio de justificación, según el cual la recolección de datos personales deberá tener un propósito general y usos específicos socialmente aceptables.

En segundo lugar, reviste vital importancia el principio de limitación de la recolección, según el cual los datos deberán ser recolectados por medios lícitos y con conocimiento y consentimiento del interesado, acotándose al mínimo necesario para alcanzar el fin perseguido.

En tercer lugar, conforme al principio de veracidad o fidelidad de la información, los datos personales que se registren deberán ser exactos, completos y actuales, rectificándose o cancelándose en su caso.

En cuarto lugar, el principio de especificación del propósito obliga a que en el momento de recolectarse los datos se informe con qué objetivo ello se hace, no pudiendo luego usarse para fines diferentes.

En quinto lugar, el principio de seguridad obliga a que todo responsable del registro de datos personales deba adoptar las medidas de seguridad adecuadas para protegerlos

12 Laura NAHABETIAN - "Protagonistas del cambio. Derechos ciudadanos y nuevas tecnologías", en X Congreso Iberoamericano de Derecho e Informática (Santiago de Chile, 2004), pág. 120 y sigtes.

13 Alvaro CANALES GIL - "La protección de datos personales como derecho fundamental” cit., pág. 265.

14 José Julio FERNANDEZ RODRIGUEZ - "Secreto e intervención de las comunicaciones en Internet” (Thomson Civitas, Madrid, 2004), pág. 56 y sigtes.

15 Carlos E. DELPIAZZO y María José VIEGA - "Lecciones de Derecho Telemático” (F.C.U., Montevideo, 2004), págs. 75 y 76 . 
contra posibles pérdidas, destrucciones o acceso no autorizado.

En sexto lugar, el principio de limitación determina que los datos personales no puedan conservarse más allá del tiempo requerido para alcanzar el objetivo para el cual fueron recolectados.

\section{Habeas data propio e impropio}

El amplio acceso a la información pública es una lógica consecuencia de la servicialidad estatal ${ }^{16}$, expresada en los principios de publicidad y transparencia frente al derecho a la información de los ciudadanos.

Se trata de una manifestación de la llamada libertad de información que comprende básicamente los siguientes tres aspectos ${ }^{17}$ :

a) el derecho a informar, es decir, a la expresión pública, que comprende la prohibición de censura explícita o encubierta (aspecto negativo) y el acceso a los medios de comunicación (aspecto positivo);

b) el derecho a informarse, o sea, a recibir información y a poder acceder a las fuentes de la misma; $y$

c) el derecho a la protección contra la información disfuncional o abusiva.

En tal sentido, la libertad de información ha sido encarada como una forma de la libertad de expresión caracterizada por su incidencia social, por exigir un soporte infraestructural para su desarrollo, y porque el receptor adquiere una particular relevancia frente al emisor; si se restara importancia al sujeto pasivo de la libertad de información, bastaría la libertad de expresión, que es claramente una libertad del sujeto para emitir y no para recibir información ${ }^{18}$.

Por eso, a veces se ha puesto el énfasis en que la libertad de información es la libertad de expresión que se realiza por los cauces de las modernas tecnologías, superando la comunicación interindividual ${ }^{19}$.

El derecho a la información es un derecho de la persona como ser espiritual ${ }^{20}$, del que pueden predicarse los atributos propios de todo derecho de la personalidad ${ }^{21}$.

16 Carlos E. DELPIAZZO - "Derecho Administrativo Uruguayo" (UNAM - Porrúa, México, 2005), pág. 7 y sigtes.; y "Marco constitucional del Derecho Administrativo Uruguayo", en V Foro Iberoamericano de Derecho Administrativo (Quito, 2006), pág. 105 y sigtes.

17 Miguel Angel EKMEKDJIAN - "Derecho a la información", (Depalma, Buenos Aires, 1992), pág. 25 y sigtes. Ramón SORIANO - "Las libertades públicas” (Tecnos, Madrid, 1990), pág. 144 y sigtes.

19 Fernando URIOSTE BRAGA - "El derecho a la información”, en Rev. Prisma (Montevideo, 1994), № 2, pág. 143 y sigtes.

20 Martín J. RISSO FERRAND - "Derecho Constitucional” (Ingranusi, Montevideo, 1998), tomo III, pág. 174 y sigtes.

${ }^{21}$ Arturo YGLESIAS PEROLO - "Derecho a la información” (F.C.U., Montevideo, 1987), pág. 41 y sigtes. 
Como un desprendimiento del derecho a la información, emerge actualmente con plena autonomía el derecho de acceso a la información pública ${ }^{22}$.

A través del mismo se potencia el control de la actividad administrativa y de quienes la realizan, permitiendo el pleno ejercicio de la soberanía del pueblo sobre sus mandatarios $y$, por ende, fortificando el sistema democrático republicano ${ }^{23}$ y coadyuvando a superar el "déficit democrático" que supone el secretismo del obrar público ${ }^{24}$.

Consecuentemente, la omisión o la negativa de la Administración a proporcionar la información requerida, obligará al interesado a acudir a los tribunales para demandarla por la vía ordinaria o de la acción de amparo si se cumplieran los supuestos de la misma, sin desmedro de otros medios jurídicos idóneos para hacer efectivo el acceso a las actuaciones administrativas.

No obstante, existe una marcada tendencia a consagrar una acción especial, generalmente llamada habeas data impropio, frente a los supuestos en que la Administración requerida se niegue o guarde silencio frente a una concreta solicitud de información.

Quiere decir que si bien el habeas data (en sentido estricto) se ha ido perfilando como una garantía de acceso a los datos personales, también se ha aplicado (por extensión) respecto de datos no personales, especialmente en poder de Administraciones públicas, con el objeto de hacer efectivo el derecho de acceso de los ciudadanos a las actuaciones administrativas.

Por otra parte, respecto a la información privada, tanto a nivel constitucional como legislativo, es cada vez más frecuente la consagración del habeas data propio como procedimiento jurisdiccional sumario tendiente a hacer efectivo el derecho de las personas a conocer, rectificar, eliminar o lo que corresponda respecto a los datos personales contenidos en bases de datos, sean automatizadas o convencionales ${ }^{25}$.

22 Marcela I. BASTERRA - "El derecho fundamental de acceso a la información pública" (Lexis Nexis, Buenos Aires, 2006), pág. 10.

23 Miguel Julio RODRIGUEZ VILLAFAÑE - "Acceso a la información pública en Argentina”, en Anuario de Derecho Constitucional Latinoamericano (Montevideo, 2004), Edición 2004, tomo II, pág. 589.

24 Luis Alberto POMED SANCHEZ - "El acceso a los archivos administrativos. El marco y la práctica administrativa”, en Rev. de Administración Pública (Madrid, 1997), № 142, pág. 471.

25 Carlos E. DELPIAZZO - "Dignidad humana y Derecho" (U.M., Montevideo, 2001), pág. 123 y sigtes.; "Protección de los datos personales en tiempos de Internet. El nuevo rostro del derecho a la intimidad”, en Rev. de Derecho de la Universidad Católica del Uruguay (Montevideo, 2002), No III, pág. 253 y sigtes.; y "El derecho a la intimidad en el ciberespacio", en Anales de las 30 Jornadas Argentinas de Informática e Investigación Operativa (Buenos Aires, 2001), pág. 51 y sigtes.; "Nueva regulación de la tutela de los datos personales y habeas data en el Derecho uruguayo", en "El Derecho en Red. Estudios en homenaje al Prof. Mario G. Losano" (Dykinson, Madrid, 2006), pág. 241 y sigtes.; "El derecho a la intimidad en el nuevo horizonte telecomunicativo", en Mariliana RICO CARRILLO (Coordinadora) - "Derecho de las nuevas tecnologías" (Edic. La Rocca, Buenos Aires, 2007), pág. 129 y sigtes.; "Marco actual de la protección de datos", en Rev. Derecho y Nuevas Tecnologías (Buenos Aires, 2006), Años 4-5, № 6-7-8, pág. 527 y sigtes. 


\section{III). Reciente normativa nacional}

Sin perjuicio de normativa anterior de distinto rango que protegía el derecho de acceso a la información pública ${ }^{26}$, cabe destacar que la ley No 18.381 de 17 de octubre de 2008 fue dictada con el específico propósito de "garantizar el derecho fundamental de las personas al acceso a la información pública” (arts. $1^{\circ}$ y $3^{\circ}$ ), entendiendo por tal "toda la que emane o esté en posesión de cualquier organismo público, sea o no estatal, salvo las excepciones o secretos establecidos por la ley, así como las informaciones reservadas o confidenciales" (art. $2^{\circ}$ ). De este modo, nuestro Derecho ha encarado la privacidad (de la información personal) y el acceso (a la información pública) como dos términos de una ecuación que no son independientes entre sí $^{27}$.

La presentación de esta ley puede realizarse mediante la referencia a los siguientes tres aspectos: el nuevo régimen tutelar que instaura, el control administrativo y el control jurisdiccional.

Respecto al primer bloque de disposiciones, se establece la disciplina de la información pública (capítulo II), haciéndolo no sólo a través de la concreta regulación de los arts. $4^{\mathrm{o}}$ a 12 , sino también mediante el reconocimiento expreso de los principios generales de publicidad $\left(\operatorname{arts.} 2^{\circ}\right.$ y $\left.4^{\circ}\right)$ y el de transparencia $\left(\operatorname{art.} 1^{\circ}\right)$, a los que ya se ha hecho referencia.

En materia de control administrativo, la ley No 18.381 dispone en su art. 19: "Créase como órgano desconcentrado de la Agencia para el Desarrollo del Gobierno de Gestión Electrónica y la Sociedad de la Información y del Conocimiento (AGESIC), dotado de la más amplia autonomía técnica, la Unidad de Acceso a la Información Pública" (inc. $1^{\circ}$ ), la que "estará dirigida por un Consejo Ejecutivo integrado por tres miembros: el Director Ejecutivo de AGESICA y dos miembros designados por el Poder Ejecutivo entre personas que por sus antecedentes personales, profesionales y de conocimiento en la materia aseguren independencia de criterio, eficiencia, objetividad e imparcialidad en el desempeño de sus cargos" (inc. $2^{\circ}$ ).

En cuanto al control jurisdiccional a través de la llamada acción de acceso a la información pública (capítulo V) -habeas data impropio- el punto de partida es el reconocimiento por el art. 22 de que "Toda persona tendrá derecho a entablar una acción judicial efectiva que garantice el pleno acceso a las informaciones de su interés".

Respecto a la procedencia de la acción, el art. 23 establece que lo será cuando cualquier sujeto obligado "se negare a expedir la información solicitada o no se expidiese

26 Carlos E. DELPIAZZO - "Habeas data. A propósito del acceso a la información pública", en Pablo MIERES y José RILA (Compiladores) - "Transparencia y ciudadanía responsable II (CLAEH, Montevideo, 2008), pág. 223 y sigtes.

27 Carlos E. DELPIAZZO - "A la búsqueda del equilibrio entre privacidad y acceso", en Carlos E. DELPIAZZO (Coordinador) - "Protección de datos y acceso a la información pública” (F.C.U., Montevideo, 2009), pág. 11 y sigtes. 
en los plazos fijados en la presente ley" (que se fija en un máximo de 20 días hábiles según el art. 13).

Por lo que refiere a la legitimación activa, el art. 24 reconoce que "La acción de acceso a la información pública podrá ser ejercida por el sujeto interesado o sus representantes, ya sean tutores o curadores y, en caso de personas fallecidas, por sus sucesores universales, en línea directa o colateral hasta el segundo grado, por sí o por medio de apoderado. En el caso de las personas jurídicas, la acción deberá ser interpuesta por sus representantes legales o los apoderados designados a tales efectos".

En cuanto a la tramitación del proceso originado en el ejercicio de la acción de acceso a la información, el mismo se organiza a imagen de la acción de amparo (art. 25 y sigtes.).

Paralelamente, en materia de información privada, tres meses antes de la que viene de reseńarse, se aprobó la ley No 18.331 de 11 de agosto de 2008, en virtud de la cual se encaró una regulación general de la protección de datos personales como derecho inherente a la persona humana (art. $\left.1^{\circ}\right)$, sin perjuicio de su extensión a las personas jurídicas en cuanto corresponda $\left(\operatorname{art.} 2^{\circ}\right)$.

La reseña de dicha ley también puede realizarse mediante la referencia a los tres aspectos antes seńalados: el nuevo régimen tutelar que instaura, el control administrativo y el control jurisdiccional.

Con relación al primero de los indicados aspectos, la ley distingue entre dato personal y dato sensible, disciplinándolos respectivamente en los capítulos III (art. 13 y sigtes.) y IV (art. 18 y sigtes.). Mientras que considera dato personal la "información de cualquier tipo referida a personas físicas o jurídicas determinadas o determinables" (art. $3^{\circ}$, lit. d), define a los datos sensibles como aquellos que "revelen origen racial y étnico, preferencias políticas, convicciones religiosas o morales, afiliación sindical e informaciones referentes a la salud o la vida sexual" (art. $3^{\circ}$, lit. e) ${ }^{28}$.

Pero la ley no agota su contenido dispositivo de fondo con dichos elementos y la concreta regulación de las bases de datos de titularidad pública (art. 24 y sigtes.) y privada (art. 28 y sigtes.) sino que, en línea con lo antes señalado, dedica el capítulo II a la enunciación y definición del alcance de los siguientes principios generales (art $5^{\circ}$ y sigtes.): legalidad, veracidad, finalidad, previo consentimiento informado, seguridad de los datos, reserva y responsabilidad.

El segundo bloque de disposiciones destacables de la ley No 18.331 está dedicado al "Organo de Control" (capítulo VII) y configura un régimen administrativo moderno de fiscalización.

28 Carlos E. DELPIAZZO - “Dignidad humana y Derecho” cit., pág. 135 y sigtes.; y Lorenzo SANCHEZ CARNELLI - "Honor, dignidad del individuo, bases de datos y habeas data”, en Rev. de Derecho Público (Montevideo, 2004), № 25, pág. 73 y sigtes. 
En virtud del art. 31, "Créase como órgano desconcentrado de la Agencia para el Desarrollo del Gobierno Electrónico y Sociedad de la Información (AGESIC), dotado de la más amplia autonomía técnica, la Unidad Reguladora y de Control de Datos Personales".

Agrega que dicha Unidad "estará dirigida por un Consejo Integrado por tres miembros: el Director Ejecutivo de la AGESIC y dos miembros designados por el Poder Ejecutivo entre personas que, por sus antecedentes personales, profesionales y conocimiento en la materia, aseguren independencia de criterio, eficiencia, objetividad e imparcialidad en el desempeño de sus cargos", los que, a excepción del Director Ejecutivo de la AGESIC, durarán cuatro años en los cargos.

En tercer lugar, en cuanto al control jurisdiccional a través de la denominada acción de babeas data (capítulo VIII) -habeas data propio- se reconoce ampliamente el derecho de toda persona "a entablar una acción judicial efectiva para tomar conocimiento de los datos referidos a su persona y de su finalidad y uso, que consten en bases de datos públicos o privados y, en caso de error, falsedad, prohibición de tratamiento, discriminación o desactualización, a exigir su rectificación, inclusión, supresión o lo que entienda corresponder" (art. 37).

Quiere decir que se consagra en forma abarcativa de todo tipo de dato personal, las diversas especies de habeas data que antes de ahora ${ }^{29}$, siguiendo calificada doctrina ${ }^{30}$, sistematicé de la siguiente manera: habeas data informativo, habeas data correctivo, habeas data cancelatorio, habeas data aditivo, y habeas data reservador.

En cuanto a la procedencia de la acción, establece el art. 38 que "El titular de datos personales podrá entablar la acción de protección de datos personales o habeas data, contra todo responsable de una base de datos pública o privada, en los siguientes supuestos:

a) cuando quiera conocer sus datos personales que se encuentran registrados en una base de datos o similar y dicha información no le hubiese sido proporcionada por el responsable de la base de datos...; o

b) cuando haya solicitado al responsable de la base de datos su rectificación, actualización, eliminación o supresión y éste no hubiese procedido a ello o dado razones suficientes por las que no corresponde lo solicitado, en el plazo previsto al efecto en la ley" (que se fija en 5 días hábiles desde la solicitud, según lo previsto en el art. 14, inc. 3º).

Respecto a la legitimación activa, el art. 39 reconoce que "La acción de habeas data podrá ser ejercida por el propio afectado titular de los datos o sus representantes, ya sean tutores o curadores y, en caso de personas fallecidas, por sus sucesores universales, en línea directa o colateral hasta el segundo grado, por sí o por medio de apoderado. En

29 Carlos E. DELPIAZZO y otros - "Protección de datos en Uruguay y el Mercosur" (F.C.U., Montevideo, 2005), pág. 26 y sigtes.

30 Oscar PUCCINELLI - "El habeas data en Indoiberoamérica" cit., pág. 220 y sigtes. 
el caso de las personas jurídicas, la acción deberá ser interpuesta por sus representantes legales o los apoderados designados a tales efectos".

En cuanto a la tramitación del proceso originado en el ejercicio de la acción de habeas data (art. 40 y sigtes.), se establece uno paralelo al de acción de acceso a la información pública, que sigue las reglas de la acción de amparo ${ }^{31}$.

\section{IV). Conclusión}

El camino hacia lo que ha dado en llamarse la "cultura del acceso" 32 implica una indudable mejora del Estado de Derecho.

En efecto, "en el ejercicio responsable del poder es imprescindible que se rinda cuenta de manera permanente a la sociedad civil de las medidas gubernamentales que se adopten. De esa manera se permite también que se controle el accionar del gobierno y de sus funcionarios y agentes. La tarea del Estado debe transparentarse para prevenir la corrupción. Hoy, más que nunca, éste es un requerimiento cívico central para una democracia creíble, posible y querible" ${ }^{33}$.

31 Marcelo BAUZA - "Régimen jurisdiccional de protección de datos personales", en anuario "Derecho Informático" (F.C.U., Montevideo, 2006), tomo VI, pág. 169 y sigtes.

32 Marcela I. BASTERRA - "El derecho fundamental de acceso a la información pública" cit., pág. 409.

33 Miguel Julio RODRIGUEZ VILLAFAÑE - "Acceso a la información pública en Argentina” cit., pág. 589. 